\title{
SuccenturiatePlacenta- An Unusual Case Presentation
}

\author{
Manohar R ${ }^{1}$, Lalitha Shivanna ${ }^{2}$, Pradeep M R ${ }^{3}$ \\ ${ }^{1}$ (Assistant Professor, Department of OBG, Mandya Institute of Medical Sciences, Mandya, India) \\ ${ }^{2}$ (Professor and head, Department of OBG, Mandya Institute of Medical Sciences, Mandya, India) \\ ${ }^{3}$ (Assistant Professor, Department of OBG, Mandya Institute of Medical Sciences,Mandya, India)
}

\begin{abstract}
A succenturiate lobe is a variation in placental morphology and refers to a smaller accessory placental lobe that is separate to the main disc of the placenta. There can be more than onesuccenturiate lobe. Here we present a case report on succenturiate lobe of placenta presenting as Antepartum haemorrhage.
\end{abstract}

Key words: Antepartum haemorrhage, bilobate, placenta, postpartumhaemorrhage, succenturiate

\section{Introduction}

The succenturiate placenta is a morphological abnormality, in which there is one or multiple accessory lobes connected to the main part of the placenta by blood vessels[1].Incidence is 16-28:10000 pregnancies[2].

\section{Case Presentation}

Smt. xx , 22 years G2P1L1 with history of 8 months of amenorrhea was admitted to the hospital on $11 / 5 / 2014$ at 12.30 AM with chief complaints of bleeding per Vagina since 6 hours, it was of sudden onset, bright red, moderate in amount and was not assosciated with pain abdomen, leaking per vagina or passage of clots. she had changed 1 pad which was fully soaked. Her married life was $2 \frac{1}{2}$ years and first pregnancy was a full term normal delivery of a single live male baby $1 \frac{1}{2}$ year old alive and healthy. Her LMP was on 6/10/2014 and EDD 13/7/2014. Her Period Of Gestation was 30.6 weeks at the time of admission.

She was previously admitted with the above complaints one month back and was hospitalized for one week. Ultrasound was done at that time which showed:

- Placenta situated in the anterior wall of the uterus with grade 1 maturity.

- Hyperechoic structure with echogenicity similar to that of placenta situated in the posterior wall about $1.3 \mathrm{~cm}$ above the internal os, Hypoechoic area measuring $32 \times 14 \mathrm{~mm}$ is seen extending from it, covering the internal os.

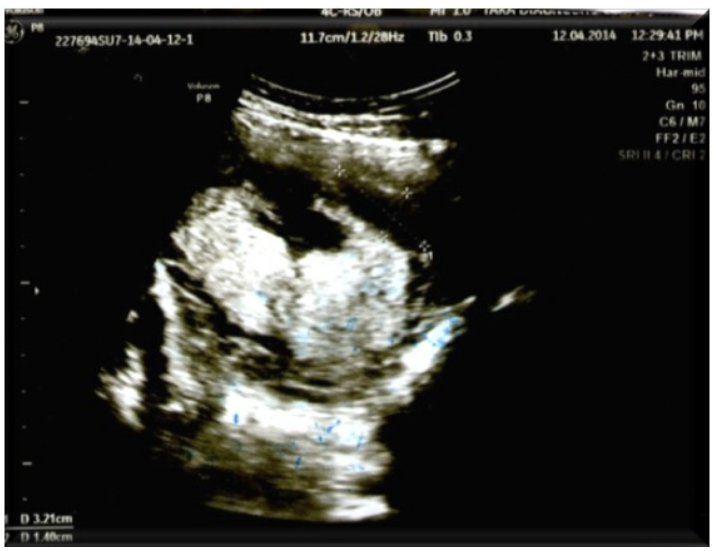

Fig.1- ultrasound showing features of succenturiate placenta

Impression-SLIUG of 27-28 weeks \pm 1 week with features suggestive of succenturiate lobe of placenta, with a small area of bleed covering the internal os.

$\mathrm{Her} \mathrm{Hb}$ was6gm/dl and all other Antenatal investigations were found to be normal. She was treated with 2 units of Packed cell Transfusion on alternate days, Inj. Betamethasone, 2 doses - 12mg IM 24 hours apart and Inj.Hydroxyprogesteronecaproate $500 \mathrm{mg}$ IM stat.After admission there were no fresh episodes of bleeding per vagina and the patient was discharged on 7th day after explaining the risk and complications of Succenturiate lobe presenting as Antepartum haemorrhage. She was advised bed rest and sexual abstinence.

At the time of present admission patient's general condition was stable, Her pulse rate was 80 beats per minute, BP-120/80 mm Hg, Cardiovascular system and Respiratory system were normal. On obstetric 
examination, Uterus was 30-32 weeks size, relaxed, Breech presentation, FHR was 130per minute, regular. Patient was treated conservatively by MacAfee regimen and risk and complications explained. Packed red blood cells were arranged and the patient was tentatively prepared for emergency LSCS if further episodes of bleeding. Within 24 hours the bleeding stopped and her general condition better. Patient was asymptomatic for 1 week, after which she had another episode of bleeding per vagina on 18/5/2014.

On examination, Pallor(++ ), pulse rate- 120 per minute, BP-90/50 mm Hg,

Cardiovascular examination- Tachycardia(++).Obstetric examination- Uterus 32 weeks size, Relaxed, Breech presentation, FHR-160 per minute.Vulvovaginal examination revealed fresh bleeding with passage of clots.

After taking high risk consent in view of maternal general condition and fetal prematurity, patient was posted for emergency LSCS after arranging blood.

Under spinal anaesthesia, emergency LSCS was done and extracted a single live preterm female baby of weight $1.88 \mathrm{Kg}$ by breech.

Intra operative and post operative period were eventful.

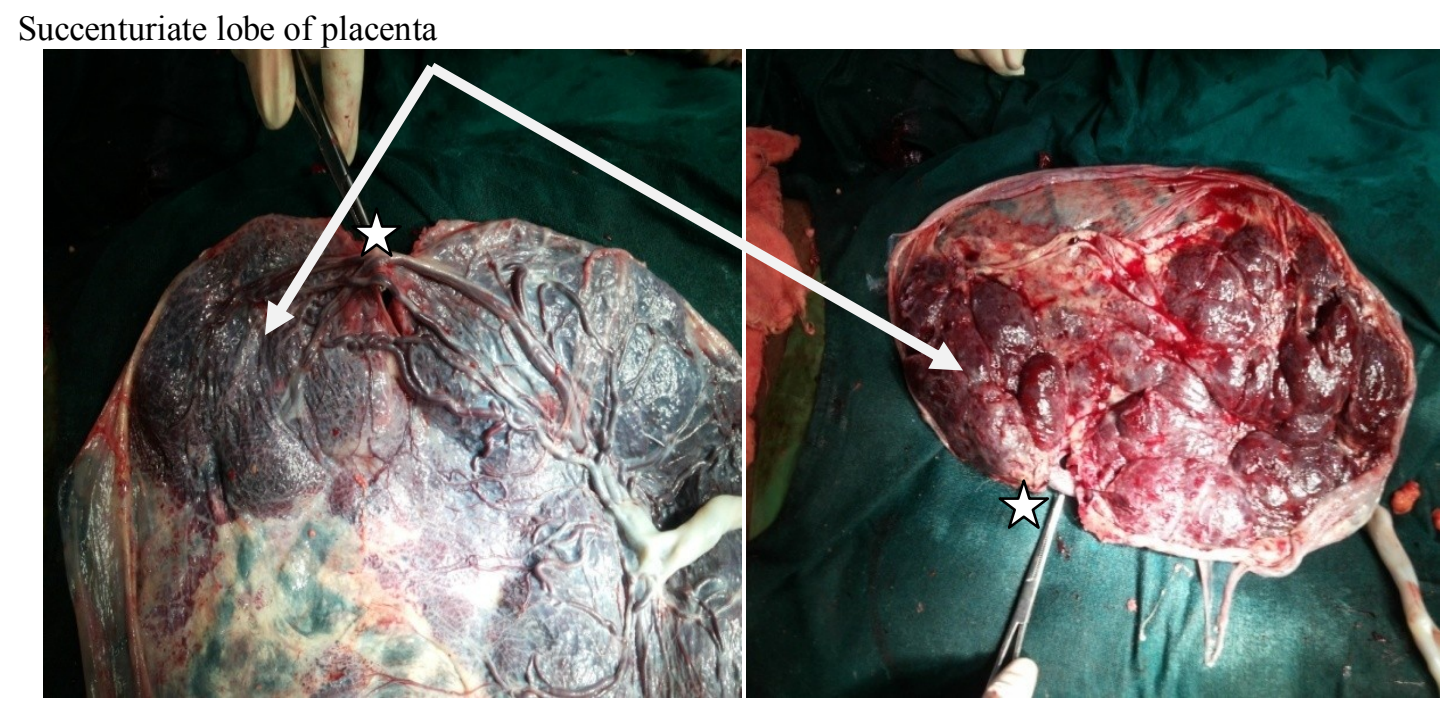

Fig.2Fetal surface of placenta.

Fig.3 Maternal surface of placenta.

Fetal vessels travelling between the membranes.

\section{Discussion}

The term succenturiate derived from Latin word "succenturio" meaning "to substitute" .Succenturiate lobes of the placenta result from focal areas of non-involution of the chorionic laeve. One or more accessory lobes are developed in the membranes at a distance from the periphery of the main placental mass. Vascular connections of the foetal origin usually connect the main placental mass to the succenturiate lobe. These accessory lobes may be single or multiple of varying size .

The risk factors associated are advanced maternal age, Primigravida, proteinuria in the first trimester of pregnancy, and major malformations in the foetus. The membranes between the lobes in such placenta can be torn during delivery, and the extra lobe can be retained after rest of placenta has been delivered, with consequent postpartum haemorrhage. In these cases, there is higher incidence of placental infarction and velamentous insertion of the umbilical cord. Unlike bipartite lobes, these accessory lobes often show areas of infarction or atrophy.

The incidence of fetal anomalies is not increased because of the presence of succenturiate placenta. The main risks of this kind of placenta occur at the time of delivery. Its antenatal recognition is important as vessels connecting the main placenta with succenturiate placenta may rupture during labour causing foetal dead. In addition, there is an increased postpartum risk of postpartum haemorrhage from retention of placental material[3].

On USG apparently separate mass of placental tissue, without recognisable bridging tissues. Seen as a smaller separate lobe of hyperechoicechotexture to the main placental disc .It is important to establish the location of any connecting vessels, and in particular to look for any vascular connections crossing the internal os[i.e.vasapraevia].Colourdoppler imaging revealed blood flow in the band like structure and was helpful in differentiating betweensuccenturiate lobe from amniotic band[4]. 
A bilobate placenta is a similar anomaly and it is clear from the literature what the exact difference if any exist[5]. It appears that some authors use bilobate when both segments of the placenta are almost equal in size and succenturiate when there is a greater difference

\section{Conclusion}

Succenturiate placenta can be diagnosed antenatally by ultrasonography and can rarely present as a cause for Antepartum haemorrhage leading on to increased maternal and perinatal morbidity and mortality. Though Succenturiate placenta occurs rarely it should be kept as a differential diagnosis for Antepartum haemorrhage

\section{References}

[1]. Jeanty P, Kirkpatrick C, Verhoogen C, Struyven J; The Succenturiate Placenta; J Ultrasound Med 2, 9-12, January 1983

[2]. Gloria Valero, MD, Philippe Jeanty, MD,PhD, Succenturiate and bilobate placenta.2000-09-02-18 www.thefetus.net.

[3]. Nelson LH, Fishburne JI, Stearns BR; Ultrasonographic description of succenturiate placenta; obstetgynecol 1977 jan;49(1 suppl):79-80

[4]. Chihara $\mathrm{H}$ et al, Prenatal diagnosis of succenturiate lobe by ultrasonography and colour imaging. Arch GynecolObstet 2000 feb;263(3):137-8

[5]. Angtuaco TL, Boyd CM, Marks SR, Quirk JG, Galwas B Sonographic diagnosis of the bilobate placenta. J Ultrasound Med 1986 Nov;5(11):672-4 